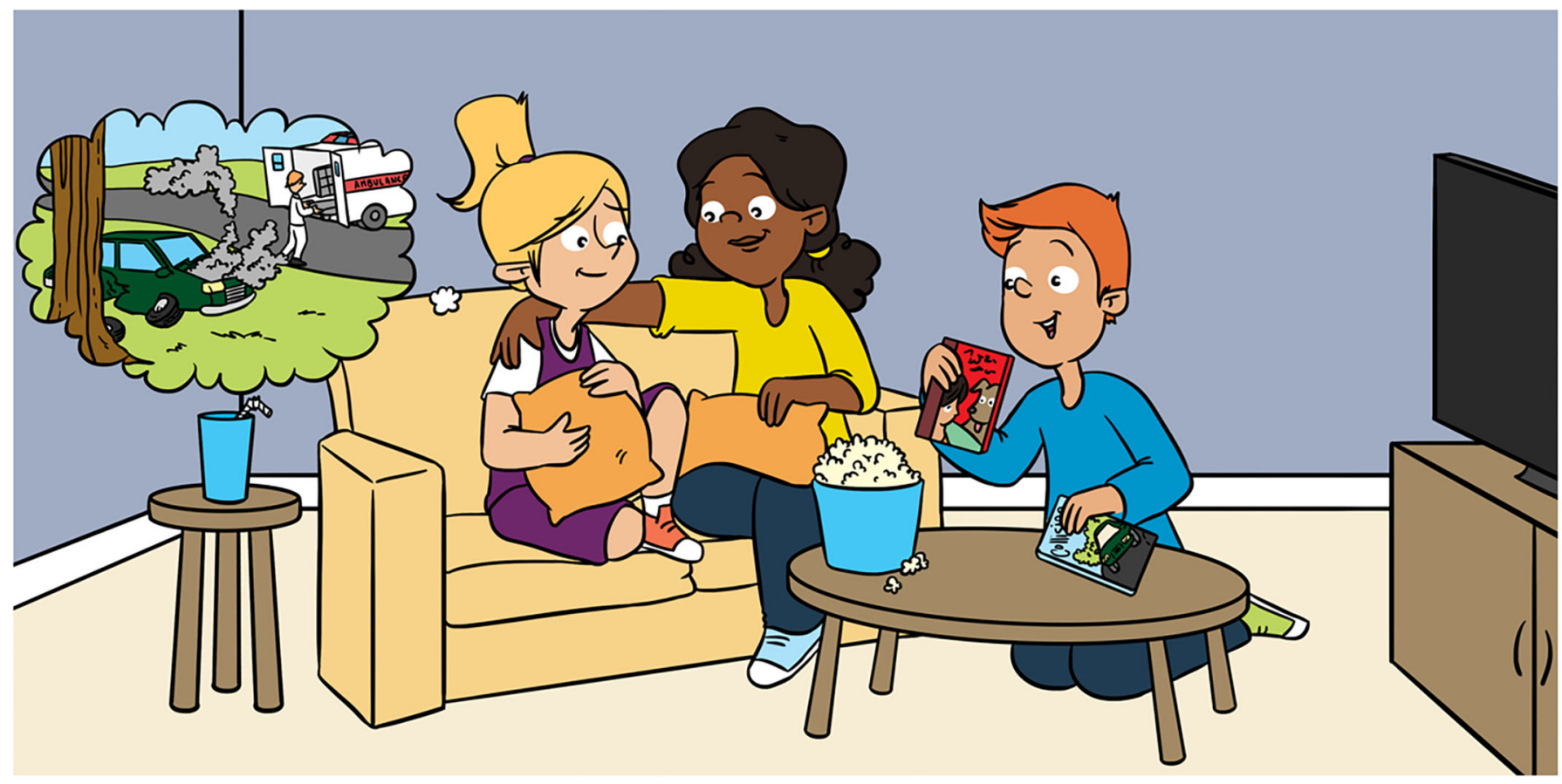

\title{
WHAT IS PTSD? DIAGNOSIS, TREATMENT, AND CHALLENGES
}

\author{
Prarthana Pilla ${ }^{1}$, Janet Y. Le ${ }^{1}$, Phoebe Lay ${ }^{1}$, Joyce Tiong ${ }^{1}$ and Nicole Osier ${ }^{2,3^{*}}$ \\ ${ }^{1}$ College of Natural Sciences, The University of Texas at Austin, Austin, TX, United States \\ ${ }^{2}$ Department of Neurology, Dell Medical School, The University of Texas at Austin, Austin, TX, United States \\ ${ }^{3}$ School of Nursing, The University of Texas at Austin, Austin, TX, United States
}

YOUNG REVIEWERS:

ALAA

AGE: 12

NOAH

AGE: 9
Post-traumatic stress disorder (PTSD) can occur when someone experiences a scary event or serious injury. This disorder can affect multiple parts of a person's life, from relationships with loved ones to performance at work. Unfortunately, PTSD is not understood well. It is considered an invisible disability, which means it can be difficult to determine if someone has PTSD just by looking at them, since they have no visible symptoms. Because of the difficulty of diagnosing PTSD, healthcare professionals are working toward checklists that can be used by all doctors for PTSD diagnosis and treatment, which will hopefully improve the care of PTSD patients. Similarly, disability activists continue to raise awareness and educate the public on PTSD. In this article, we will discuss the causes of PTSD, its effects on daily life, diagnosis, treatment, and the importance of showing kindness toward people with this invisible disability. 
POST-TRAUMATIC STRESS DISORDER (PTSD)

A mental health condition that develops after a distressing event and results in variable symptoms that impact an individual's life and relationships.

\section{TRAUMA}

A deeply distressing or disturbing event that may result in physical or psychological harm.

\section{INTRODUCTION}

Post-traumatic stress disorder (PTSD) is a big term, but we can understand it by breaking it down. Trauma is a deeply distressing experience, like a physical injury or an emotional experience. "Post-" is a prefix that means "after," so "post-traumatic" means that a person has experienced something scary in the past. The final part of the term, "stress disorder," refers to problems that will affect the person afterwards. Putting it altogether, PTSD is a mental health condition that develops from a distressing event. PTSD does not occur in any one group of people or result from one specific type of incident; it can arise from various experiences.

People with PTSD might experience bad memories or nightmares that remind them of the previous traumatic incident. They sometimes also avoid people or places associated with the event. For example, veterans with PTSD might choose to avoid war museums because such places may remind them of combat. People with PTSD might also be especially sensitive to certain sights or sounds. Veterans might find fireworks disturbing, as the sounds may remind them of loud guns. Similarly, a survivor of a major earthquake might find a news report on another natural disaster disturbing.

Very few people who experience traumatic events actually develop PTSD. For this reason, researchers are working hard to figure out why some people develop PTSD while others do not. Scientists, doctors, nurses, and other healthcare professionals think development of PTSD has to do with the way that our external environments (such as where we live and our support systems) can interact with our genes. Previously, it was thought that PTSD was caused only by genes. However, we now know that our genes can be affected by everything around us. Some people are more likely to develop PTSD after a traumatic event if they carry certain genes. Some people might also be at risk of developing PTSD if the traumatic event turns certain genes on or off. Genes can be turned on or off, similar to light switches (Figure 1). A traumatic event can flip these switches just enough for a person to develop PTSD. Clearly, there are a lot of different factors that could lead to the development of PTSD. However, we still need to better understand these factors and their interactions.

\section{EFFECTS OF PTSD ON DAILY LIFE}

PTSD can have many effects on a person's daily life and relationships. Researchers have found that the more severe a person's PTSD symptoms are, the more aggressive the person's behavior tends to be [1]. People with severe PTSD may act out toward their friends and family or avoid talking about their feelings. At times, they may seem disconnected from everything around them, i.e., they might not respond if their friends and family try to talk to them. They may also 
Figure 1

PTSD is believed to be caused by a combination of genes and environment.

Genes can be switched "on" and "off," similar to a light switch. A

traumatic event can sometimes flip these switches just enough for a person to develop PTSD.
DIAGNOSTIC AND

\section{STATISTICAL}

MANUAL OF

MENTAL

\section{DISORDERS}

A handbook that is used by healthcare professionals to guide the diagnosis of mental disorders.

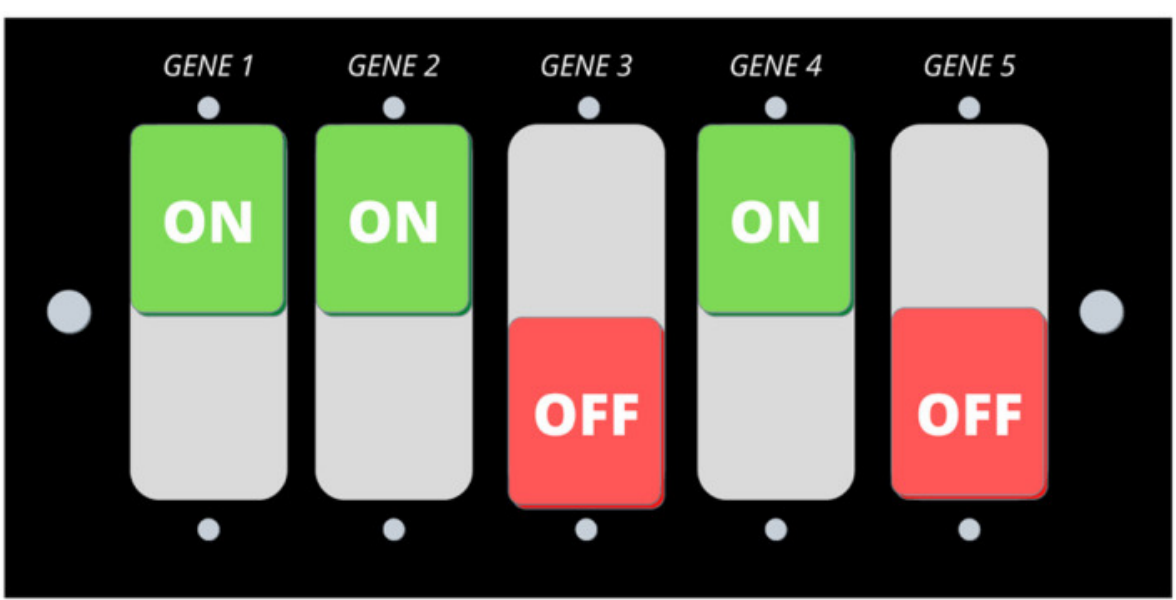

Figure 1

avoid potentially triggering places or events, which can make going to friends' houses or birthday parties difficult. If people with PTSD do not explain why they do not visit, their loved ones may be confused and hurt. The effects of PTSD on daily life and relationships are challenging, both for people with PTSD and their loved ones, but resources are available. Resources, such as the National Institute of Mental Health (NIMH), a support group, or talking to a therapist can be helpful.

\section{HOW IS PTSD DIAGNOSED?}

There are several steps to determine if someone has PTSD (Figure 2) [2]. The first step is screening, during which the person is asked a few questions about their experiences. One common question set used in screening is called the Brief Trauma Questionnaire. This questionnaire asks 10 questions about serious life events, such as major injuries or anything that put the person's life in danger, to assess the level of trauma the person has experienced [3]. The second step involves using a universal checklist created by healthcare professionals and researchers to make an official diagnosis. This checklist is made up of criteria for diagnosing someone with PTSD, such as certain behavioral and bodily symptoms. The criteria can be found in the Diagnostic and Statistical Manual of Mental Disorders (DSM), a book that lists and describes all known mental illnesses. For someone to be diagnosed with PTSD, that person must have had symptoms for at least 1 month. After diagnosis, doctors track the person's symptoms and response to treatment over time. This step includes self-reports that patients complete each time they go to the doctor's office. One commonly used self-report is a checklist from the DSM, which includes 20 questions about how often a patient has experienced different PTSD symptoms. 
Figure 2

There are several steps involved in diagnosing and treating PTSD: screening, official diagnosis, treatment, and follow-up.

\section{Figure 3}

There are several types of treatment for PTSD. Examples include kinds of therapy called cognitive processing therapy, cognitive-behavioral conjoint therapy, and group therapy, as well as medications.

\section{COGNITIVE}

PROCESSING

\section{THERAPY (CPT)}

An individual works with a therapist to identify and refocus negative thoughts based on writing about lived experiences and their impact.

\section{COGNITIVE}

BEHAVIORAL

CONJOINT

\section{THERAPY (CBCT)}

A therapist helps an individual strengthen their relationships with others though improved problem-solving skills.

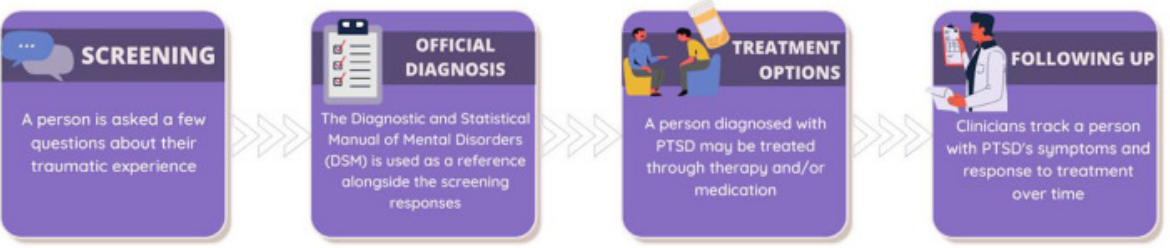

Figure 2

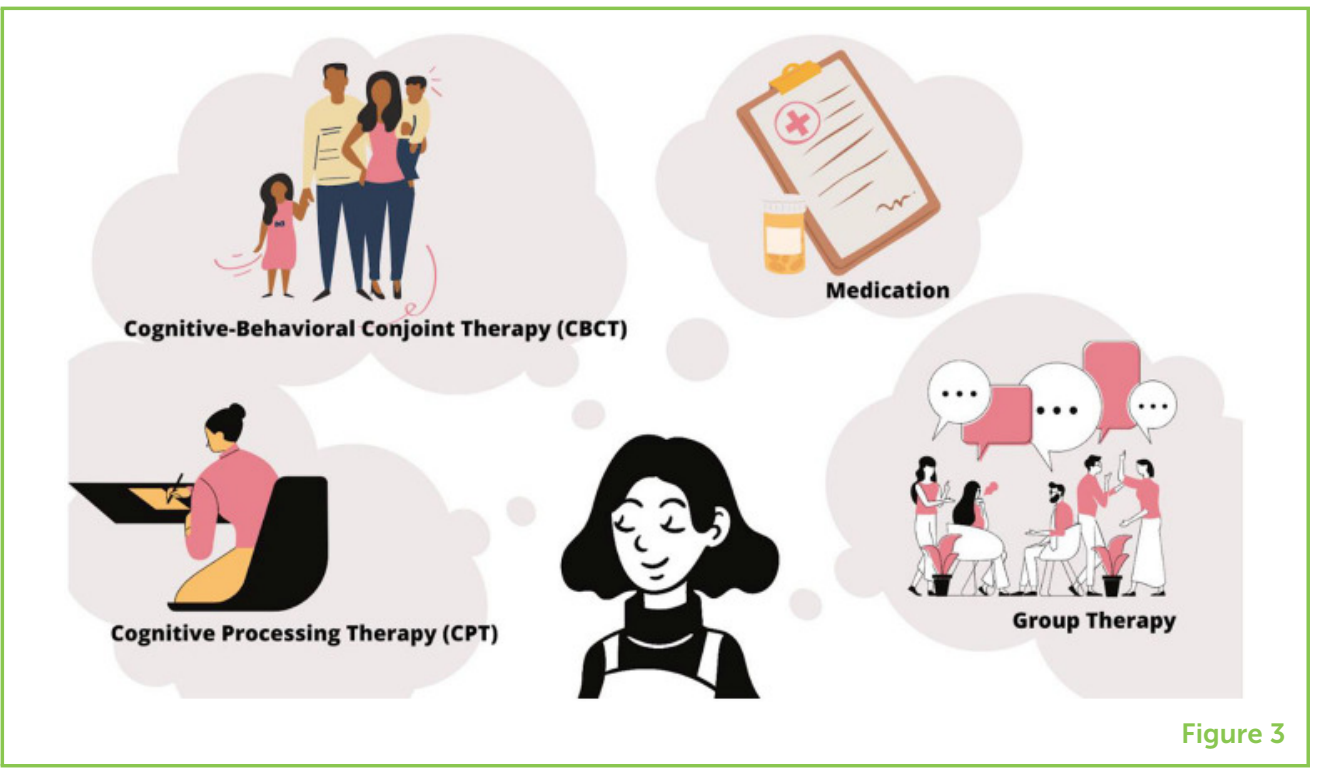

\section{HOW IS PTSD TREATED?}

PTSD treatments can include medications, individual therapy, or group therapy (Figure 3). In therapy sessions, people typically participate in specific types of therapy called cognitive processing therapy (CPT) or cognitive behavioral conjoint therapy (CBCT). In CPT, people write about how their experiences have impacted their lives. The therapist helps patients pinpoint negative feelings and refocus their thoughts on the positive [2]. CBCT focuses on improving relationships by having patients work with their loved ones to improve problem-solving skills [1]. The other form of PTSD treatment is medication, which requires less time and effort from the patient, but must be taken under the watch of a healthcare team. Several medications used to treat PTSD are classified as selective serotonin reuptake inhibitors (SSRIs), which are drugs commonly used to treat depression and PTSD. SSRIs have been shown to improve mood and decrease anxiety [4]. Unfortunately, there is currently no definite cure for PTSD. People living with PTSD might manage their symptoms by continuing medication and/or therapy, seeking family counseling, and consciously avoiding triggers. 
SELECTIVE

SEROTONIN

REUPTAKE

INHIBITORS (SSRIS)

A type of medication that increases levels of a chemical in the brain that positively affects mood and emotions.

\section{TRIGGER}

\section{Events}

or circumstances that cause a person to recall a previous

traumatic experience.

\section{INVISIBLE}

\section{DISABILITIES}

A type of condition that limits a person's activities, but may not be visible to others based on their appearance; a person who uses a wheelchair has a visible disability, while a person with post-traumatic stress disorder has an invisible disability.

\section{TRIGGERS AND TRIGGER WARNINGS}

To keep PTSD in check, people with this disorder should try to avoid or mentally prepare themselves for situations that remind them of their traumatic event, known as triggers. In PTSD, a trigger sets off the stress response by reminding the person of the traumatic event, and can worsen PTSD symptoms. For example, violent movies with a lot of fighting can be triggering for a soldier who experienced war. Trigger warnings can help people avoid such triggers. Trigger warnings are notifications that warn people about potentially triggering types of content. They can be used at the beginning of certain movies, TV shows, or even TikToks. Trigger warnings allow people with and without PTSD to prepare themselves for the traumatic content, which can make viewing the trigger less shocking.

However, it is difficult to decide what should come with a trigger warning [5]. Take, for example, two movies that both feature soldiers in combat but have different titles. Should the movie with a clearly upsetting title, such as "Soldiers at War" or the one with a less obvious title, such as "Survival," come with a warning? The audience must also be considered. A book with triggering content might be popular in one country but unpopular in another. As a result, teachers in the first country may assume that their students with PTSD have heard of the book and decide not to provide a trigger warning. Teachers in the second country may assume that their students with PTSD have not heard of the book and provide the warning. For these reasons, psychologists and disability advocates are coming up with more universal ideas of what needs a trigger warning.

\section{PTSD IS AN INVISIBLE DISABILITY}

Disabilities can fall under two main groups: invisible and visible. Visible disabilities, as the name suggests, are those you can see. For example, someone whose legs are paralyzed might have trouble moving normally and will need a wheelchair to get around. Invisible disabilities like PTSD are different, because you cannot tell whether a person has one just by looking at them. As a result, others may not realize that people with PTSD are different and may need certain types of help in daily life when compared to people without PTSD. For example, a boss might have two employees with PTSD but only "see" symptoms in one of them. The employee with the more visible PTSD may be allowed to leave work early each day to attend therapy, while the employee with the less visible PTSD must work as many hours as everyone else. The employee with invisible PTSD may have trouble focusing at work or finding time to attend therapy [6]. Moreover, if something is out of sight, it is often out of mind. Unfortunately, this means that PTSD often receives less attention from scientists and health care providers than many visible disabilities do. All of this tells us that, even though we cannot see invisible disabilities, it is important 
to remember that the experiences of people who have them are just as valid as the experiences of people with visible disabilities.

\section{CONCLUSION}

PTSD is a disorder that people may develop because of their past experiences. It can cause changes in mood, emotions, and interactions with friends and family. A person experiencing these changes can be affected by others' opinions about the disorder, causing them to feel ashamed or uncomfortable. This can cause PTSD sufferers to hide their condition, attempting to be seen as "normal." Pretending not to have PTSD can lead to depression, anxiety, and other mental illnesses [6]. Therefore, it is important to be kind and respectful toward those with disabilities, visible or invisible. By treating people with PTSD fairly, we can make them comfortable enough to be themselves and speak openly about their disabilities. Ultimately, this will lead to a better understanding of PTSD and its effects, which can help increase awareness of invisible disabilities and ensure better lives for those affected.

\section{REFERENCES}

1. Monson, C. M., Taft, C. T., and Fredman, S. J. 2009. Military-related PTSD and intimate relationships: from description to theory-driven research and intervention development. Clin. Psychol. Rev. 29:707-14. doi: 10.1016/j.cpr. 2009.09.002

2. Lancaster, C. L., Teeters, J. B., Gros, D. F., and Back, S. E. 2016. Posttraumatic stress disorder: overview of evidence-based assessment and treatment. J. Clin. Med. 5:105. doi: 10.3390/jcm5110105

3. National Center for PTSD. 2018. Brief Trauma Questionnaire (BTQ). U.S. Department of Veterans Affairs; c1995-2007. PTSD: National Center for PTSD. Available online at: https://www.ptsd.va.gov/professional/assessment/temeasures/brief_trauma_questionnaire_btq.asp (accessed May 6, 2020).

4. National Center for PTSD. 2020. Medications for PTSD. U.S. Department of Veteran Affairs. PTSD: National Center for PTSD. Available online at: https://www.ptsd.va.gov/understand_tx/meds_for_ptsd.asp (accessed May 6, 2020).

5. Lockhart, E. 2016. Why trigger warnings are beneficial, perhaps even necessary. First Amend. Stud. 50:59-69. doi: 10.1080/21689725.2016.1232623

6. Santuzzi, A., Waltz, P., Finkelstein, L., and Rupp, D. 2014. Invisible disabilities: unique challenges for employees and organizations. Ind. Organ. Psychol. 7:204-19. doi: 10.1111/iops.12134

SUBMITTED: 02 July 2020; ACCEPTED: 05 February 2021;

PUBLISHED ONLINE: 02 March 2021.

EDITED BY: Danijela Serbic, Royal Holloway, University of London, United Kingdom 


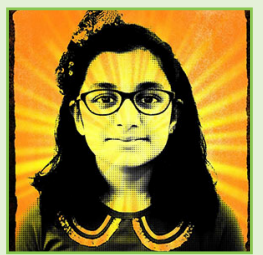

CITATION: Pilla P, Le JY, Lay P, Tiong J and Osier N (2021) What Is PTSD? Diagnosis, Treatment, and Challenges. Front. Young Minds 9:579592. doi: 10.3389/ frym.2021.579592

CONFLICT OF INTEREST: The authors declare that the research was conducted in the absence of any commercial or financial relationships that could be construed as a potential conflict of interest.

COPYRIGHT (c) 2021 Pilla, Le, Lay, Tiong and Osier. This is an open-access article distributed under the terms of the Creative Commons Attribution License (CC BY). The use, distribution or reproduction in other forums is permitted, provided the original author(s) and the copyright owner(s) are credited and that the original publication in this journal is cited, in accordance with accepted academic practice. No use, distribution or reproduction is permitted which does not comply with these terms.

\section{YOUNG REVIEWERS}

\section{ALAA, AGE: 12}

I am a generalist and an avid reader. I love learning, traveling, and eating good quality cheese, pasta, and chocolate. In my free time I enjoy coding, drawing, coloring, watching cartoons and educational videos. My favorite sport is badminton. I am also a varsity badminton player and I love being on the court. In the future I aspire to work in the field of science or aviation and be a great role model for all the girls/women around the world.

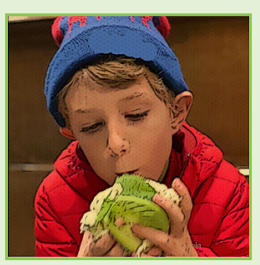

\section{NOAH, AGE: 9}

I am a 9 year old kid named Noah. I like to code and read during my free time, and can type at over 40 words per minute. I like to play the piano, and know two guitar chords. My favorite song to play is "Turkish March," by Ludwig van Beethoven. When I grow up, I would like to become a teacher.

\section{AUTHORS}

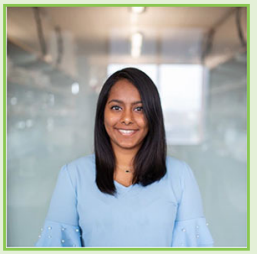

\section{PRARTHANA PILLA}

I am a junior at the University of Texas at Austin pursuing a Bachelor of Science in Human Biology with a minor in Social Work and a certificate in Ethics and Leadership in Healthcare. In the future, I hope to pursue a career that incorporates social justice in the field of medicine. In my free time I love to dance, do puzzles, and read.

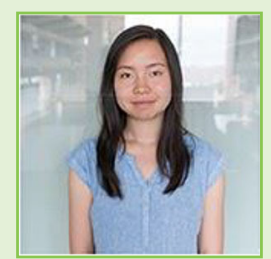

\section{JANET Y. LE}

I am a junior at the University of Texas at Austin pursuing a Bachelor of Science in Human Biology with a certificate in Ethics and Leadership in Healthcare. After I graduate, I hope to attend medical school and stay involved in biomedical research. In my spare time, I like to ski, try new restaurants, do arts and crafts, and explore parks. 

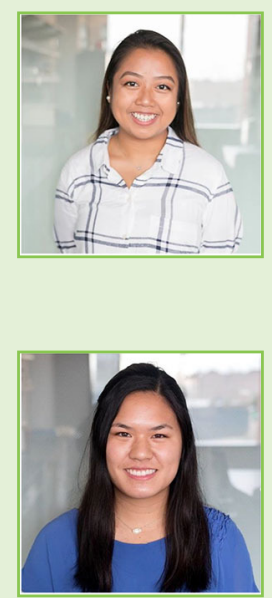

\section{PHOEBE LAY}

I am a senior at the University of Texas at Austin, graduating with a Bachelor of Science and Arts in Human Development and Family Sciences, with a minor in Business. I hope to attend medical school and become a pediatrician. In my free time, I enjoy volunteering, running, cooking, painting, and getting artsy with graphic design!

\section{JOYCE TIONG}

I am a junior at the University of Texas at Austin pursuing a Bachelor of Science and Arts in Biology and a certificate in Spanish for healthcare professionals. After graduating, I hope to attend medical school. I have strong interests in urban studies, public health, and community engagement. In my free time, I enjoy baking, playing tennis, and photography!

\section{NICOLE OSIER}

I am a principal investigator at University of Texas at Austin. I have bachelor's degrees in Nutritional Science and Nursing from Michigan State University, and a Ph.D. from the University of Pittsburgh. My goal is to better understand what makes some individuals recover better than others after head injury. My ultimate goal is to apply new knowledge to help doctors and nurses treat people with head injuries, so patients recover as well as possible. To learn more about my laboratory visit my publicly available website: https://nicoleosier.wixsite. com/osierlaboratory/ or follow aosierlaboratory on Facebook, twitter, or Instagram. In my free time, I enjoy spending time with my spouse and cats and traveling the world. *nicoosier@utexas.edu 